\title{
Suppression of Cisplatin-Induced Vomiting by Cannabis sativa in Pigeons: Neurochemical Evidences
}

\author{
Ihsan Ullah ${ }^{1,2 *}$, Fazal Subhan ${ }^{2}$, Javaid Alam ${ }^{2,3}$, Muhammad Shahid ${ }^{2}$ and \\ Muhammad Ayaz ${ }^{*}$
}

\begin{abstract}
${ }^{1}$ Department of Pharmacy, University of Swabi, Swabi, Pakistan, ${ }^{2}$ Department of Pharmacy, University of Peshawar Peshawar, Pakistan, ${ }^{3}$ Drug and Herbal Research Centre, Faculty of Pharmacy, University Kebangsaan Malaysia, Kuala Lumpur, Malaysia, ${ }^{4}$ Department of Pharmacy, University of Malakand, Chakdara, Pakistan
\end{abstract}

\section{OPEN ACCESS}

Edited by:

Fabricio A. Pamplona, Entourage Phytolab, Brazil

Reviewed by:

Maria Grazia Morgese

University of Foggia, Italy

Daniel Souza Monteiro De Araújo,

Federal Fluminense University, Brazil

*Correspondence:

Ihsan Ullah

ihsanmkd@gmail.com

ihsanmkd@uoswabi.edu.pk

Muhammad Ayaz

ayazuop@gmail.com

Specialty section:

This article was submitted to

Neuropharmacology,

a section of the journal

Frontiers in Pharmacology

Received: 29 November 2017

Accepted: 28 February 2018

Published: 16 March 2018

Citation:

Ullah I, Subhan F, Alam J, Shahid M and Ayaz M (2018) Suppression of Cisplatin-Induced Vomiting by Cannabis sativa in Pigeons:

Neurochemical Evidences.

Front. Pharmacol. 9:231. doi: 10.3389/fphar.2018.00231
Cannabis sativa (CS, family Cannabinaceae) has been reported for its anti-emetic activity against cancer chemotherapy-induced emesis in animal models and in clinics. The current study was designed to investigate CS for potential effectiveness to attenuate cisplatin-induced vomiting in healthy pigeons and to study the impact on neurotransmitters involved centrally and peripherally in the act of vomiting. Highperformance liquid chromatography system coupled with electrochemical detector was used for the quantification of neurotransmitters 5-hydroxytryptamine $(5 \mathrm{HT})$, dopamine (DA) and their metabolites; Di-hydroxy Phenyl Acetic acid (Dopac), Homovanillic acid (HVA), and 5-hydroxy indole acetic acid (5HIAA) centrally in specific brain areas (area postrema and brain stem) while, peripherally in small intestine. Cisplatin (7 mg/kg i.v.) induce emesis without lethality across the $24 \mathrm{~h}$ observation period. CS hexane fraction (CS-HexFr; $10 \mathrm{mg} / \mathrm{kg}$ ) attenuated cisplatin-induced emesis 65.85\% $(P<0.05)$; the reference anti-emetic drug, metoclopramide (MCP; $30 \mathrm{mg} / \mathrm{kg}$ ), produced $\sim 43.90 \%$ reduction $(P<0.05)$. At acute time point $\left(3^{\text {rd }} \mathrm{h}\right)$, CS-HexFr decreased $(P<0.001)$ the concentration of $5 \mathrm{HT}$ and $5 \mathrm{HIAA}$ in the area postrema, brain stem and intestine, while at $18^{\text {th }} \mathrm{h}$ (delayed time point) CS-HexFr attenuated $(P<0.001)$ the upsurge of $5 \mathrm{HT}$ caused by cisplatin in the brain stem and intestine and dopamine in the area postrema. CS-HexFr treatment alone did not alter the basal neurotransmitters and their metabolites in the brain areas and intestine except 5HIAA and HVA, which were decreased significantly. In conclusion the anti-emetic effect of CS-HexFr is mediated by antiserotonergic and anti-dopaminergic components in a blended manner at the two different time points, i.e., $3^{\text {rd }}$ and $18^{\text {th }} \mathrm{h}$ in pigeons.

Keywords: cisplatin, emesis, Cannabis sativa, pigeon, neurotransmitters

\section{INTRODUCTION}

Cytotoxic agents like cisplatin and cyclophosphamide have the side effects of nausea and vomiting most feared by patients undergoing chemotherapy (Hesketh et al., 2003a). These stressful side effects often result in poor compliance and even refusal of treatment (Tanihata et al., 2000; Hesketh, 2008). The $\mathrm{D}_{2}$ receptor blocker "metoclopramide" was found to be effective against chemotherapy induced vomiting (CIV) at higher doses, where the anti-emetic effect is reported to be mediated 
through antagonism of 5-hydroxytryptamine type $3\left(5 \mathrm{HT}_{3}\right)$ receptors (Coronas et al., 1975; Miner and Sanger, 2012). These findings led to the discovery of $5 \mathrm{HT}_{3}$ receptor antagonists (Ondansetron, etc.).

Dopamine (DA), 5-hydroxytryptamine (5HT), and neuropeptide substance $\mathrm{P}$ are involved in emetic circuitry. The neurotransmitter 5HT (Serotonin) is primarily responsible for the initiation of the vomiting produced by cisplatin (Grunberg and Koeller, 2003). Up to $95 \%$ of $5 \mathrm{HT}$ is present in the enterochromaffin (EC) cells in the gastrointestinal mucosa along with substance P (Diemunsch and Grelot, 2000; Minami et al., 2003). The noxious stimulus caused by highly emetogenic chemotherapy (HEC) agents like cisplatin results in the release of 5HT (Wolff and Leander, 1997; Percie du Sert et al., 2011). The released $5 \mathrm{HT}$ then activates $5 \mathrm{HT}_{3}$ receptors on vagal afferents which stimulate the brain centers to initiate the vomiting response (Hesketh et al., 2003b). Furthermore, in human and animal studies, there is evidence for the increased level of the 5-HT metabolite, 5-Hydroxy Indole Acetic Acid (5HIAA, urine) (Cubeddu et al., 1995; Veyrat-Follet et al., 1997), 5HT in the intestinal mucosa (ileal segment), Tryptophan Hydroxylase (TPH, ileum), Aromatic L-amino Decarboxylase (AADC, ileum) (Endo et al., 1993) and in the brain stem (Minami, 1995), following cisplatin treatment. Furthermore, a decrease in Monoamine Oxidase (MAO, ileum) has also been reported (Endo et al., 1993). This enhancement in 5HT biosynthesis and reduction in degradation ultimately led to the upsurge of serotonin which initiates the vomiting response (Ullah, 2013).

The selective activation of $\mathrm{D}_{2}$ receptors, localized in the limbic system, hypothalamus, amygdala and in the brain stem emetic circuitry trigger the vomiting response (Le Moine and Bloch, 2004). This involvement of dopamine receptors advocates dopamine as important mediator for vomiting act. Dopaminergic agonists like apomorphine have been reported to be emetic in a variety of species including dogs (Foss et al., 1998), ferrets (Osinski et al., 2003, 2005), least shrew (Darmani et al., 1999), and humans (Schofferman, 1976). The emetic action of apomorphine and loperamide has been suggested to be mediated in the chemoreceptor trigger zone/area postrema through stimulation of dopamine receptors. Where, the ablation of area postrema abolished the vomiting response advocating the involvement of area postrema in the mediation of vomiting by apomorphine and loperamide (Miller and Leslie, 1994; Yoshikawa et al., 1996).

The identification of cannabinoid receptors resulted in the discovery of endocannabinoids (Pacher et al., 2006). Delta-9Tetrahydrocannabinol $\left(\Delta^{9}\right.$-THC) and synthetic cannabinoids exert their cannabimimetic effects via $\mathrm{CB}_{1}$ receptors (Mackie and Stella, 2006). $\mathrm{CB}_{1}$ receptors are primarily located centrally and peripherally while $\mathrm{CB}_{2}$ receptors occur mainly on immune cells (Pertwee, 2006). Furthermore, a family of nuclear hormone receptor $\operatorname{PPAR}(\alpha, \beta$, and $\gamma)$ are also been reported to be involved in the mediation of some effects in analgesia, antiinflammatory, neuroprotection, cardiovascular, gastrointestinal, and anti-tumor properties of some cannabinoids (O'sullivan, 2016). Endocannabinoids like oleoylethanolamide (OEA) and palmitoylethanolamide (PEA) are reported to activate PPAR $\alpha$. Other endocannabinoids including noladin ether, virodhamine, 2-arachidonoyl-glycerol, and Anandamide are also shown to stimulate PPAR $\alpha$ and transient receptor potential vanilloid type 1 (TRPV1) cation channel. In continuation, Synthetic cannabinoids like WIN55,212-2 activates the transcriptional activity of PPAR $\alpha$ and PPAR $\gamma$ (Brown, 2007; O'sullivan, 2016; Stampanoni Bassi et al., 2017). Activation of the Endocannabinoid system, PPAR $\gamma$ and $\mathrm{CB} 1$ receptors are associated with decrease in the dopaminergic activity in the basal ganglia and levodopa induced abnormal involuntary movements (AIMs) which can be extrapolated to the anti-emetic effect of CS in the brain stem emetic center (Martinez et al., 2015; Stampanoni Bassi et al., 2017).

Cannabinoids have been shown to affect neuronal circuits that modulate nausea, vomiting, and other gastrointestinal functions. Evidence is emerging regarding the interaction of cannabinoid $\left(\mathrm{CB}_{1}\right)$, serotonin $\left(5 \mathrm{HT}_{3}\right)$, neurokinin-1 $\left(\mathrm{NK}_{1}\right)$ and dopamine receptors $\left(\mathrm{D}_{2}\right.$ and $\left.\mathrm{D}_{3}\right)$, implicating an important role for cannabinoids in vomiting circuits. The old era of neurotransmitter understanding advocate primarily the involvement of the monoaminergic neurotransmitters especially serotonergic system, while the late phase is associated with monoaminergic system excluding the serotonergic system (Tanihata et al., 2000). The current literature provide evidences for the substantial overlapping of serotonergic, dopaminergic, and neurokininergic mechanisms for the entire time course of cisplatin-induced vomiting (Saito et al., 2003; Darmani et al., 2009; Higgins et al., 2012).

Considering the relevance of DA and 5HT in cisplatininduced vomiting, this study was designed to evaluate the participation of these monoamine neurotransmitters and their metabolites in cisplatin-induced vomiting, and to examine the impact of Cannabis sativa (CS) extract on neurotransmitters implicated in the act of vomiting in specific brain areas and intestine in pigeons. Cannabis sativa hexane fraction was selected based on our previous studies where it was proved to be anti-emetic against cisplatin-induced vomiting in pigeon model (Ullah et al., 2012).

\section{MATERIALS AND METHODS}

\section{Animals}

Pigeons of either sex (mixed breed, Department of Pharmacy, University of Peshawar, Peshawar, Pakistan) weighing between 250 and $350 \mathrm{~g}$ were used. They were housed in groups of eight $(n=8)$ at $22-26^{\circ} \mathrm{C}$ under a $12 \mathrm{~h}$ light/dark cycle and had free access to food (locally available food; Millet + Wheat) and water before and during experimentation. All of the experimental procedures were approved by the Ethical Committee of the Department of Pharmacy, University of Peshawar (Ref. No. 5/EC/Pharm) and were in accordance with the UK Animal Scientific Procedure Act, 1986 (Ullah, 2013).

\section{Drugs and Chemicals}

High-performance liquid chromatography (HPLC) grade acetonitrile (99.9\%), methanol (99.9\%), 1-octane sulfonic acid sodium salt (>98\%) (Fisher Scientific, United Kingdom), sodium 
dihydrogen orthophosphate (99\%) and ethylene diamine tetra acetic acid ( $\geq 99 \%)$ (EDTA) were purchased from the Merck local distributor in Peshawar, Pakistan. Noradrenaline ( $\geq 98 \%)$, DOPAC $(\geq 98 \%)$, dopamine $(\geq 99 \%)$, 5HIAA ( $\geq 98 \%)$, HVA $(\geq 98 \%)$, and serotonin $(\geq 99 \%)$, were from Acros Organics, Belgium. Cisplatin ( $\geq 99.9 \%)$ was from Korea United Pharm., Inc. (South Korea). Metoclopramide (MCP; $\geq 98 \%$ ) was purchased in solution from GlaxoSmithKline (GSK Pakistan, Ltd.). Commercial grade $n$-Hexane was from Haq Chemicals Peshawar (Pakistan). The plant was collected at a farm, from Malakand Division (Khyber Pukhtoonkhwa, Pakistan) at its bloom season and was authenticated by Prof. Dr. Muhammad Ibrar, Department of Botany, University of Peshawar, a specimen was preserved in the herbarium for future reference (voucher No. 8717) (Ullah, 2013).

\section{Extraction of Cannabis sativa}

Leaves and flowering tops of Cannabis sativa plant were separated, shade dried, coarsely ground and then extracted as shown in the extraction scheme (Figure 1) (Ali et al., 2017; Ayaz et al., 2017).

\section{Drug Formulation}

Cisplatin was dissolved in normal saline by heating up to $60^{\circ} \mathrm{C}$ and then cooled up to $40-45^{\circ} \mathrm{C}$ before administration (Ullah et al., 2014). Cannabis sativa $n$-hexane fraction (CS-HexFr) was dissolved in absolute ethanol, mixed with emulsifier and made the volume with distilled water in such a way that the final mixture consists of ethanol: emulsifier: distilled water in a ratio of 5: 5: 90 (Feigenbaum et al., 1989a; Ullah, 2013).

\section{Drug Administration}

Cotton wool and methylated spirit were used to sterilize the skin prior to drug administration. Intravenous (Cisplatin) and

\section{Cannabis sativa (coarsely grinded plant material)

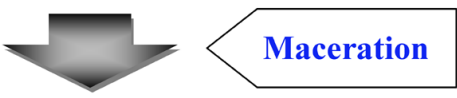 \\ $01 \mathrm{~kg}, \boldsymbol{n}$-hexane

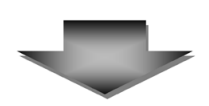 \\ Extract

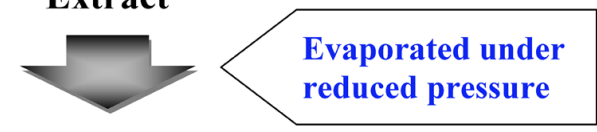 \\ CS-HexFr \\ (yield = 101 gm)}

FIGURE 1 | Extraction scheme for Cannabis sativa to get $n$-hexane fraction (Ullah, 2013). The plant material was macerated twice with $n$-hexane. The extract was filtered and concentrated under reduced pressure using rotary evaporator to get CS-HexFr. intramuscular (Treatment) administrations were done through brachial wing vein and chest muscle, respectively using Neoject $2 \mathrm{ml}$ non-pyrogenic syringes with sharp painless needles $\left(27 \mathrm{G} \times 1 / 2^{\prime \prime}\right.$ for the i.v. route, and $23 \mathrm{G} \times 1^{\prime \prime}$ for the i.m. route). Immediately, after the last injection, the animals were put back in the specially designed confining/observation cages and the number of Retching plus Vomiting $(R+V)$ and latency to first vomit were recorded for $24 \mathrm{~h}$. At the end of experiment, body weight loss was calculated. Subsequently, the animals were decapitated to terminate the experiment (Ullah, 2013).

\section{Anti-emetic Assay}

On the day of experiment, the pigeons were placed in individual cages specially designed for video observation. Cisplatin at the dose of $7 \mathrm{mg} / \mathrm{kg}$ was administered intravenously via the brachial wing vein at $t=0$ (Ullah et al., 2014). The behavior of the pigeons was then recorded for $24 \mathrm{~h}$. Food and water were available during the observation period and each animal was used only once. The vomiting response with or without oral expulsion was considered as one vomiting episode (Preziosi et al., 1992). The latency to first vomit and the number of vomiting episodes were recorded. A vomiting episode was considered complete when the pigeon adapted relaxed posture. Jerking episodes, which are indicative of vomiting intensity, were also recorded. In these studies, $C S$ fraction and MCP or respective vehicles, were administered $30 \mathrm{~min}$ before cisplatin administration, In case of twice (BD) administration of CS the second dose was administered intramuscularly at $12^{\text {th }}$ of cisplatin administration (Ullah, 2013).

\section{Tissue Sampling for Neurotransmitters Analysis}

Two discrete parts of the brain (brain stem and area postrema) as well as the intestinal samples $5-6 \mathrm{~cm}$ from the pylorus (initial segment of Jejunum) were collected for the neurotransmitter analysis and the effects of CS-HexFr and MCP were investigated. The dissection of brain parts was carried out according to the atlas of Karten and Hodos (1967) and Duvernoy and Risold (2007). In brief, after decapitation of experimental animals, the dorsal surface of the skull was exposed by making an incision along the mid line and the temporal muscles were stripped off to expose skull bone. After exposing the skull, bones, and meninges were carefully removed in a way to expose the brain hemispheres and especially to make brain stem prominent from the ventral aspect. The long strip of capillaries stretching from the obex on the median line to the lateral angles of the fourth ventricle (area postrema) was dissected followed by dissection of brain stem. Jejunal samples of about $2 \mathrm{~cm}$ were rapidly removed and washed with ice cold saline. The collected samples were rapidly frozen on an ice plate and stored at $-80^{\circ} \mathrm{C}$ until analysis (Ullah, 2013).

\section{Determination of Neurotransmitters and Their Metabolites}

Tissue samples were homogenized in cold $0.2 \%$ perchloric acid (PCA) at $5000 \mathrm{rpm}$ with the help of Teflon glass homogenizer (Wise stir HS 30 E). After centrifugation 
(Centurion, United Kingdom) at $12000 \mathrm{~g} / \mathrm{min}\left(4^{\circ} \mathrm{C}\right)$ and filtered through a 0.45 micron filter. Neurotransmitters and their metabolites were analyzed using High-Performance Liquid Chromatography system (HPLC, Shimadzu, Japan) coupled with Electrochemical Detection (ECD, ESA Coulochem III model 5300), a pump (model LC-20AT), and an analytical column (Teknokroma $3 \times 150,3 \mathrm{um}$ ). The mobile phase consisted of $94 \mathrm{mM}$ sodium dihydrogen orthophosphate, $40 \mathrm{mM}$ Citric acid, $2.3 \mathrm{mM}$ sodium 1-octane sulfonic acid, $50 \mathrm{uM}$ EDTA, and 10\% acetonitrile $(\mathrm{pH} 3)$. The flow rate was maintained at $0.6 \mathrm{~mL} / \mathrm{min}$. The standards used were noradrenaline hydrochloride (NA), 3, 4dihydroxyphenylacetic acid (DOPAC), dopamine hydrochloride (DA), 5-hydroxyindole-3-acetic acid (5HIAA), Homovanillic acid (HVA), and serotonin (5HT). The HPLC method already reported by our laboratory (Ullah et al., 2014) was used where all the neurotransmitters and their metabolites were separated within $13 \mathrm{~min}$ (Ullah, 2013).

\section{Statistical Analysis}

The differences between means were evaluated using a one way analysis of variance (ANOVA) followed by Dunnett or Tukey multiple comparison tests. $P<0.05$ was considered as statistically significant. The animals which showed complete suppression of Retching Plus Vomiting $(R+V)$ were not included in statistical analysis for latency. Data represent the mean \pm SEM unless otherwise indicated.

\section{RESULTS}

\section{Anti-emetic Effect of Cannabis sativa Hexane Fraction (CS-HexFr)}

Cisplatin at the dose of $7 \mathrm{mg} / \mathrm{kg}$ (Ullah et al., 2014) induced reliable $R+V$ in all the animals tested with intense vomiting occurring in the first $3 \mathrm{~h}$ while the treatments attenuated it Figure 2 and Table 1.

In these experiments, cisplatin-induced $R+V$ following a latency of $\sim 67$ min that comprised $\sim 41$ episodes. $C S$ hexane fraction (CS-HexFr; 5, 10, and $15 \mathrm{mg} / \mathrm{kg}$ ) attenuated cisplatininduced $R+V$ in non-dose-dependent manner (Figure 3), showing significant reduction with $10 \mathrm{mg} / \mathrm{kg}$ once (OD) and twice (BD) dosing up to $17 \pm 3.4(58.53 \%$ protection) and
A

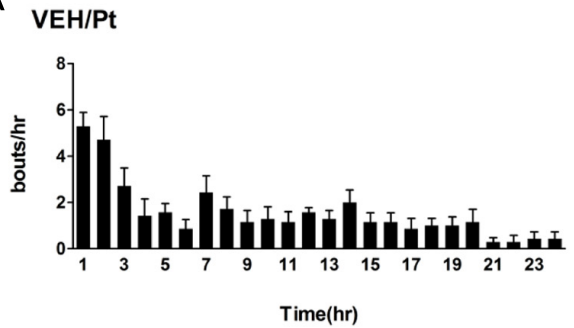

B

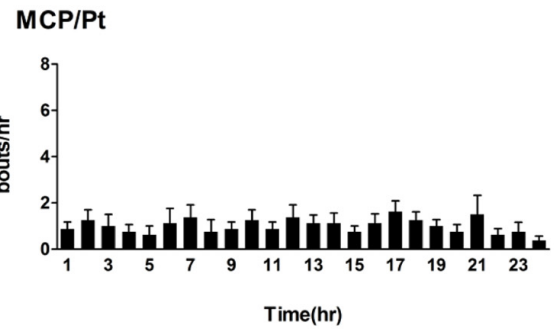

C

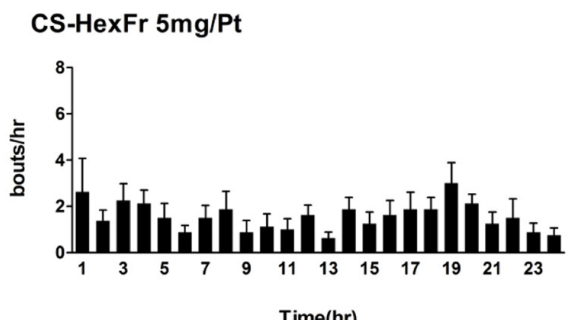

D

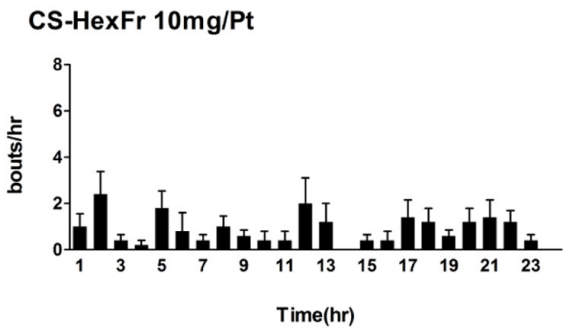

E

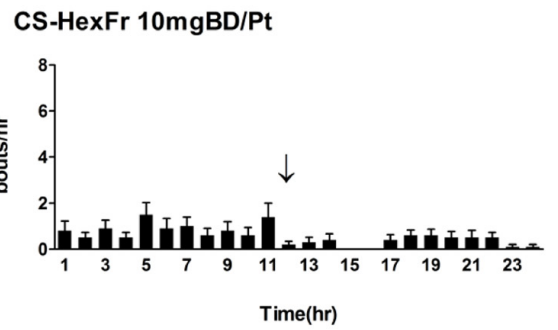

$\mathbf{F}$

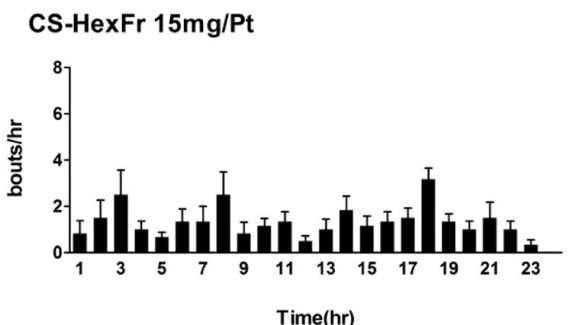

FIGURE 2 | Sketch of cisplatin-induced emesis in pigeons and the effect of treatments (A-F) on cisplatin induced emesis profile during a $24 \mathrm{~h}$ observation period. (A) Cisplatin control, (B) Metoclopramide treatment, (C) Cannabis sativa hexane fraction $5 \mathrm{mg}$ treatment, (D) Cannabis sativa hexane fraction $10 \mathrm{mg}$ treatment, (E) Cannabis sativa hexane fraction $10 \mathrm{mg} \mathrm{BD}$ treatment; the arrow indicates second dose administration, and (F) Cannabis sativa hexane fraction $15 \mathrm{mg}$ treatment. Data represents the mean \pm SEM of the total numbers of retches + vomits occurring during $1 \mathrm{~h}$ intervals $(n=7-8)$. 
TABLE 1 | Effect of Cannabis sativa hexane fraction (CS-HexFr) or standard metoclopramide (MCP) on cisplatin-induced Retching plus Vomiting ( $+V$ ) and jerking during a $24 \mathrm{~h}$ observation period.

\begin{tabular}{|c|c|c|c|c|c|c|}
\hline Drug treatment & Dose and route & $\begin{array}{c}\text { Pigeons } \\
\text { n/vomited }\end{array}$ & $\begin{array}{c}R+V \text { Episodes } \\
\text { Mean } \pm \text { SEM }\end{array}$ & $\begin{array}{l}\text { Latency }(\mathrm{min}) \\
\text { Mean } \pm \text { SEM }\end{array}$ & $\begin{array}{c}\text { Jerks } \\
\text { Mean } \pm \text { SEM }\end{array}$ & $\begin{array}{l}\text { Wt loss (\%) } \\
\text { Mean } \pm \text { SEM }\end{array}$ \\
\hline Vehicle + Cisplatin & $2 \mathrm{ml} / \mathrm{kg}$ i.m. $+7 \mathrm{mg} / \mathrm{kg}$ i.v. & $8 / 8$ & $41 \pm 2.4$ & $67 \pm 3.2$ & $570 \pm 63$ & $15.1 \pm 1.4$ \\
\hline MCP + Cisplatin & 30 mg/kg i.m. + 7 mg/kg i.v. & $8 / 8$ & $23 \pm 1.1^{* *}$ & $195 \pm 41.2^{*}$ & $361 \pm 25$ & $11.9 \pm 1.1$ \\
\hline \multirow[t]{4}{*}{ CS-HexFr + Cisplatin } & 5 mg/kg i.m. + 7 mg/kg i.v. & $7 / 7$ & $33 \pm 5.9$ & $185 \pm 41$ & $429 \pm 69$ & $9.1 \pm 1.2$ \\
\hline & 10 mg/kg i.m. + 7 mg/kg i.v. & $6 / 6$ & $17 \pm 3.4^{* *}$ & $269 \pm 114$ & $301 \pm 73$ & $9.4 \pm 1.7$ \\
\hline & 15 mg/kg i.m. + 7 mg/kg i.v. & $8 / 8$ & $27 \pm 2.1$ & $231 \pm 39$ & $435 \pm 51$ & $10.3 \pm 1.1$ \\
\hline & 10 mg/kg i.m BD + 7 mg/kg i.v. & $8 / 8$ & $14.1 \pm 2.9^{* *}$ & $254 \pm 70^{*}$ & $239 \pm 59^{*}$ & $8.9 \pm 1.0^{*}$ \\
\hline
\end{tabular}

${ }^{*} P<0.05,{ }^{* *} P<0.01$ as compared to cisplatin control (ANOVA followed by Tukey's post hoc test).

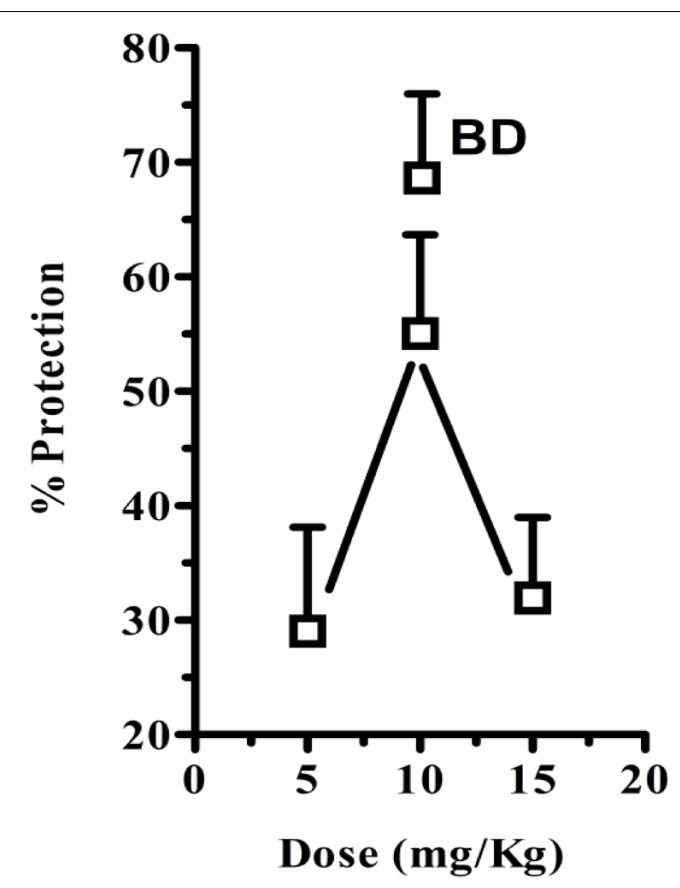

FIGURE 3 | Percent protection observed by either once daily dose of Cannabis sativa hexane fraction (OD; 5,10 , and $15 \mathrm{mg} / \mathrm{kg}$ ) or twice daily (BD; $10 \mathrm{mg} / \mathrm{kg}$ ) $30 \mathrm{~min}$ before cisplatin challenge. The values represent mean \pm SEM of $5-8$ determinations.

$14.1 \pm 2.9(65.85 \%$ protection $)$, respectively $(P<0.01$; Table 1$)$ during $24 \mathrm{~h}$ of observation period. The CS-HexFr was found to be effective as it suppressed $R+V$ up to $16 \mathrm{~h}$ of observation period while standard metoclopramide provided protection up to $8 \mathrm{~h}$ (Figure 4). CS-HexFr $10 \mathrm{mg}$ BD and standard MCP increased the latency to first vomit significantly $(P<0.01)$.

None of the treatments induced vomiting when administered alone.

\section{Effect of MCP or CS-HexFr on Cisplatin-Induced Jerks and Weight Loss}

In the cisplatin control group, animals lost $\sim 15 \%$ of their starting body weight. The body weight loss in the standard MCP (30 $\mathrm{mg} / \mathrm{kg})$ treated group was $11.9 \pm 1.1 \%$, while CS-HexFr $(10 \mathrm{mg} / \mathrm{kg} \mathrm{BD})$ reduced body weight loss up to $8.9 \%(P<0.05$,
Table 1). All other treatments failed to reduce body weight loss significantly. The jerking behavior (reflects the vomiting intensity in pigeons; one vomiting episode may contain 2-80 jerks) observed in cisplatin control and standard MCP groups were $570 \pm 63$ and $361 \pm 25$, respectively, while no treatment decreased the jerking behavior up to the observation period $(24 \mathrm{~h})$ except CS-HexFr (10 mg/kg BD) where the jerking episodes were reduced significantly $(570 \pm 63 \rightarrow 239 \pm 59 ; P<0.05$, Table 1$)$.

\section{Effect of Standard MCP or CS-HexFr on Basal Level of Neurotransmitters and Their Metabolites in the Brain Areas and Small Intestine}

The standard MCP treatment reduced the concentration of 5HIAA in the area postrema $(P<0.05)$ and brain stem $(P<0.001)$ as compared to basal level. In addition, the decrease in the concentration of HVA was also observed in the area postrema $(P<0.05$, Table 2$)$. As depicted in Table 2 , treatment with CS-HexFr $(10 \mathrm{mg} / \mathrm{kg})$ had no significant effects on NA, DA and its metabolites DOPAC and HVA, 5HT and its metabolite 5HIAA in the brain areas (AP and BS) and intestine. Though, the concentration of DA at the level of AP and intestine was increased significantly $(P<0.001)$ as compared to basal level.

\section{Effect of Standard MCP or CS-HexFr on the Level of Neurotransmitters and Their Metabolites in the Brain Areas and Small Intestine at $3^{\text {rd }}$ Hour After Cisplatin Administration}

Cisplatin treatment significantly increased the concentration of 5-hydroxytryptamine (5HT) in the brainstem and intestine $(P<0.001$; Table 3$)$ as compared to basal level, while a non-significant increase was observed in the area postrema. In addition, cisplatin also caused a significant increase in the concentration of 5HIAA in the area postrema $(P<0.05)$, brain stem $(P<0.001)$, and intestine $(P<0.001)$. The treatment with standard MCP at the dose of $30 \mathrm{mg} / \mathrm{kg}$ failed to change the concentration of NA, DOPAC, DA, and HVA in all the brain areas (AP and BS) and intestine, but reduced the concentration of 5HT in the area postrema, brain stem, and intestine significantly $(P<0.05-0.001)$ as compared to cisplatin control (Table 3). In addition to its inhibitory effects on 5HT, MCP also decreased 


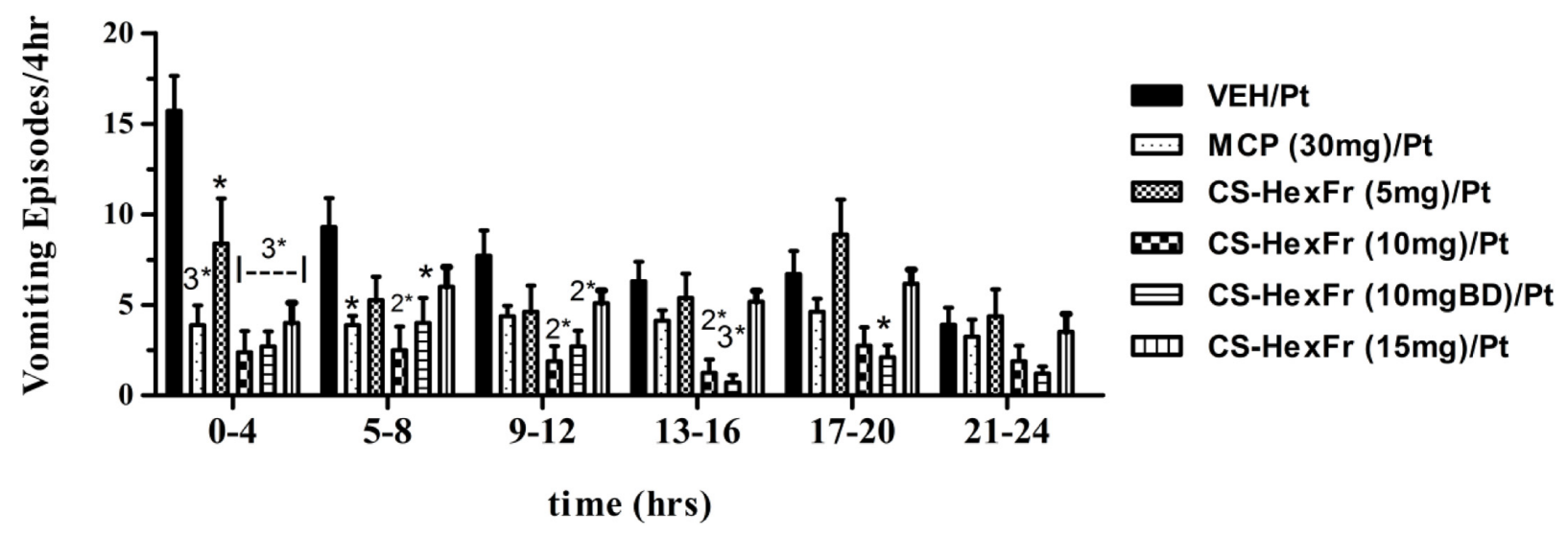

FIGURE 4 | The vomiting suppression time profile in pigeons of standard metoclopramide (MCP; $30 \mathrm{mg} / \mathrm{kg}$ ) or Cannabis sativa hexane fraction (CS-HexFr; 5,10 , and $15 \mathrm{mg} / \mathrm{kg}$ ) against cisplatin-induced vomiting during a $24 \mathrm{~h}$ observation period; each bar represents the mean \pm SEM of vomiting episodes occurring during $4 \mathrm{~h}$ periods $(n=5-8)$. Values significantly different from cisplatin control are denoted as ${ }^{*} P<0.05,2^{*} P<0.01,3^{*} P<0.001$ (ANOVA followed by Tukey's post hoc test).

TABLE 2 | Effect of standard metoclopramide (MCP) or Cannabis sativa hexane fraction (CS-HexFr) on basal level of neurotransmitters (ng/mg tissue wet weight) and their metabolites in brain areas and the small intestine of pigeons.

\begin{tabular}{|c|c|c|c|c|c|c|}
\hline Treatment & NA & DOPAC & DA & 5HIAA & HVA & $5 \mathrm{HT}$ \\
\hline Vehicle & $0.590 \pm 0.011$ & $0.401 \pm 0.101$ & $0.530 \pm 0.046$ & $0.141 \pm 0.021$ & $0.793 \pm 0.067$ & $0.059 \pm 0.010$ \\
\hline CS-HexFr 10 mg & $0.579 \pm 0.500$ & $0.094 \pm 0.026$ & $1.888 \pm 0.547^{* * *}$ & $0.260 \pm 0.087$ & $1.335 \pm 0.323$ & $0.126 \pm 0.106$ \\
\hline \multicolumn{7}{|l|}{ Brain stem } \\
\hline Vehicle & $0.089 \pm 0.030$ & $0.059 \pm 0.013$ & $0.164 \pm 0.065$ & $0.063 \pm 0.020$ & $0.040 \pm 0.001$ & $0.010 \pm 0.010$ \\
\hline CS-HexFr 10 mg & $0.012 \pm 0.003$ & $0.098 \pm 0.002$ & $0.342 \pm 0.039$ & $0.038 \pm 0.003$ & $0.015 \pm 0.000$ & $0.031 \pm 0.000$ \\
\hline \multicolumn{7}{|l|}{ Intestine } \\
\hline Vehicle & $0.121 \pm 0.039$ & $0.053 \pm 0.010$ & $0.070 \pm 0.050$ & $0.048 \pm 0.049$ & $0.051 \pm 0.024$ & $0.071 \pm 0.023$ \\
\hline MCP 30 mg & $0.153 \pm 0.029$ & $0.061 \pm 0.021$ & $0.060 \pm 0.017$ & $0.089 \pm 0.012$ & $0.124 \pm 0.100$ & $0.057 \pm 0.011$ \\
\hline CS-HexFr 10 mg & $0.021 \pm 0.001$ & $0.063 \pm 0.029$ & $1.291 \pm 0.273^{* * *}$ & $0.219 \pm 0.045$ & $0.102 \pm 0.042$ & $0.011 \pm 0.002$ \\
\hline
\end{tabular}

${ }^{*} P<0.05,{ }^{* * *} P<0.001$ as compared to saline (ANOVA followed by Tukey's post hoc analysis; $n=6-8$ ).

5HIAA concentration in both the brain areas (AP and BS) and intestine significantly $(P<0.01-0.001$, Table 3$)$. CSHexFr $(10 \mathrm{mg} / \mathrm{kg})$ significantly reduced the 5HIAA and 5HT concentrations in the brain areas (AP and BS) and intestine $(P<0.001)$ while no effects were seen on the levels of NA and DOPAC. On the contrary, CS-HexFr $(10 \mathrm{mg})$ treatment caused an increase in the concentration of DA in AP, BS, and intestine that was significant $(P<0.001)$ as compared to the cisplatin control (Table 3).

\section{Effect of Standard MCP or CS-HexFr on the Level of Neurotransmitters and Their Metabolites in the Brain Areas and Small Intestine at $18^{\text {th }}$ Hour After Cisplatin Administration}

Cisplatin increased the level of DA significantly $(P<0.001)$ in the AP, while a non-significant trend toward increase was observed in the brain stem (Table 4). 5HT concentrations were also raised in the area postrema $(P<0.01)$, brain stem $(P<0.001)$ and intestine
$(P<0.001)$, without effecting the levels of NA, DOPAC, 5HIAA, HVA (Table 4). Treatment with standard metoclopramide (MCP; $30 \mathrm{mg} / \mathrm{kg}$ ) significantly decreased the upsurge of DA in the area postrema $(P<0.001$; Table 4). Furthermore, a decrease in the concentration of 5HT was also observed in the area postrema $(P<0.01)$, brain stem and intestine $(P<0.001)$ and 5HIAA concentration $(P<0.01)$ in the area postrema as compared to cisplatin control (Table 4). Cannabis sativa hexane fraction (CS-HexFr) at the dose of $10 \mathrm{mg} / \mathrm{kg}$ decreased significantly $(P<0.001)$ the upsurge in the concentration of DA in the brain area of $\operatorname{AP}(P<0.001)$ while decrease in 5HT was observed in the brain stem and intestine $(P<0.001$; Table 4$)$.

\section{DISCUSSION}

In the present study, we screened $n$-hexane fraction of Cannabis sativa (CS-HexFr) against cisplatin-induced retching and vomiting $(R+V)$ in the pigeon vomiting model, where it was found to be effective to attenuate cisplatin-induced $R+V$. 


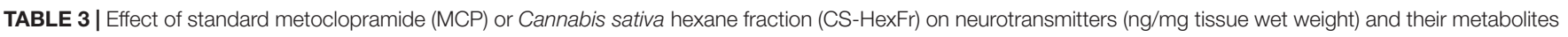
in brain areas and small intestine $3 \mathrm{~h}$ after cisplatin treatment in pigeons.

\begin{tabular}{|c|c|c|c|c|c|c|}
\hline Treatment & NA & DOPAC & DA & 5HIAA & HVA & $5 \mathrm{HT}$ \\
\hline \multicolumn{7}{|l|}{ Area postrema } \\
\hline Vehicle & $0.605 \pm 0.298$ & $0.217 \pm 0.100$ & $0.618 \pm 0.218$ & $0.087 \pm 0.039$ & $0.805 \pm 0.166$ & $0.113 \pm 0.060$ \\
\hline Cisplatin & $1.799 \pm 1.101$ & $0.302 \pm 0.091$ & $0.091 \pm 0.021$ & $0.401 \pm 0.109^{\#}$ & $0.459 \pm 0.139$ & $0.265 \pm 0.101$ \\
\hline MCP 30 mg & $0.110 \pm 0.078$ & $0.142 \pm 0.050$ & $0.310 \pm 0.137$ & $0.026 \pm 0.006^{* *}$ & $0.040 \pm 0.021$ & $0.030 \pm 0.005^{*}$ \\
\hline CS-HexFr 10 mg & $0.265 \pm 0.034$ & $0.638 \pm 0.133$ & $2.142 \pm 0.387^{* * *}$ & $0.045 \pm 0.012^{* * *}$ & $1.140 \pm 0.162$ & $0.030 \pm 0.010^{* *}$ \\
\hline \multicolumn{7}{|l|}{ Brain stem } \\
\hline Vehicle & $0.119 \pm 0.043$ & $0.031 \pm 0.030$ & $0.253 \pm 0.152$ & $0.013 \pm 0.001$ & $0.090 \pm 0.016$ & $0.018 \pm 0.000$ \\
\hline Cisplatin & $0.081 \pm 0.021$ & $0.161 \pm 0.127$ & $0.029 \pm 0.001$ & $0.040 \pm 0.003^{\# \# \#}$ & $0.027 \pm 0.002$ & $0.147 \pm 0.010^{\# \# \#}$ \\
\hline MCP 30 mg & $0.041 \pm 0.021$ & $0.039 \pm 0.003$ & $0.013 \pm 0.002$ & $0.021 \pm 0.001^{* * *}$ & $0.023 \pm 0.001$ & $0.008 \pm 0.000^{* * *}$ \\
\hline CS-HexFr 10 mg & $0.026 \pm 0.001$ & $0.013 \pm 0.001$ & $0.436 \pm 0.020^{* * *}$ & $0.009 \pm 0.001^{* * *}$ & $0.013 \pm 0.004$ & $0.010 \pm 0.003^{* * *}$ \\
\hline \multicolumn{7}{|l|}{ Intestine } \\
\hline Vehicle & $0.337 \pm 0.045$ & $0.087 \pm 0.035$ & $0.133 \pm 0.031$ & $0.032 \pm 0.010$ & $0.089 \pm 0.046$ & $0.048 \pm 0.051$ \\
\hline Cisplatin & $0.301 \pm 0.012$ & $0.011 \pm 0.010$ & $0.031 \pm 0.004$ & $0.305 \pm 0.016^{\# \# \#}$ & $0.041 \pm 0.010$ & $0.545 \pm 0.105^{\# \# \#}$ \\
\hline MCP 30 mg & $0.109 \pm 0.040^{*}$ & $0.029 \pm 0.001$ & $0.246 \pm 0.183$ & $0.031 \pm 0.006^{* * *}$ & $0.067 \pm 0.030$ & $0.041 \pm 0.005^{* * *}$ \\
\hline CS-HexFr 10 mg & NA & $0.067 \pm 0.039$ & $0.920 \pm 0.130^{* * *}$ & $0.003 \pm 0.001^{* * *}$ & $0.030 \pm 0.012$ & $0.001 \pm 0.000^{* * *}$ \\
\hline
\end{tabular}

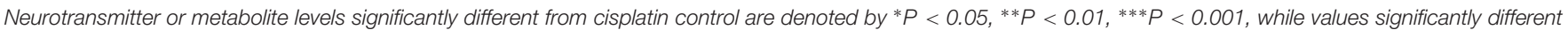
from basal levels are denoted by $P<0.05$, \#\#\# $P<0.001$ (ANOVA followed by Tukey's post hoc analysis; $n=6-8$ ).

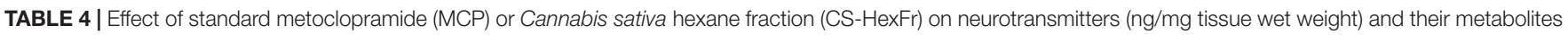
in brain areas and the small intestine at $18 \mathrm{~h}$ after cisplatin treatment in pigeons.

\begin{tabular}{|c|c|c|c|c|c|c|}
\hline Treatment & NA & DOPAC & DA & 5HIAA & HVA & $5 \mathrm{HT}$ \\
\hline \multicolumn{7}{|l|}{ Area postrema } \\
\hline Vehicle & $0.494 \pm 0.063$ & $0.337 \pm 0.138$ & $0.491 \pm 0.169$ & $0.219 \pm 0.030$ & $0.854 \pm 0.121$ & $0.010 \pm 0.001$ \\
\hline Cisplatin & $0.279 \pm 0.063$ & $0.061 \pm 0.011$ & $5.066 \pm 1.301^{\# \# \#}$ & $0.201 \pm 0.014$ & $0.548 \pm 0.121$ & $0.160 \pm 0.041^{\# \#}$ \\
\hline MCP 30 mg & $0.182 \pm 0.092$ & $0.062 \pm 0.030$ & $0.098 \pm 0.029 * * *$ & $0.019 \pm 0.002^{* *}$ & $0.322 \pm 0.178$ & $0.008 \pm 0.003^{* *}$ \\
\hline CS-HexFr 10 mg & $0.392 \pm 0.052$ & $0.254 \pm 0.154$ & $0.818 \pm 0.232^{* * *}$ & $0.104 \pm 0.016$ & $0.294 \pm 0.144$ & $0.105 \pm 0.011$ \\
\hline \multicolumn{7}{|l|}{ Brain stem } \\
\hline Vehicle & $0.072 \pm 0.005$ & $0.074 \pm 0.015$ & $0.070 \pm 0.030$ & $0.118 \pm 0.021$ & $0.027 \pm 0.014$ & $0.001 \pm 0.000$ \\
\hline Cisplatin & $0.079 \pm 0.010$ & $0.011 \pm 0.001$ & $0.163 \pm 0.031$ & $0.032 \pm 0.030$ & $0.010 \pm 0.001$ & $0.119 \pm 0.011^{\# \# \#}$ \\
\hline MCP 30 mg & $0.008 \pm 0.003$ & $0.002 \pm 0.001$ & $0.019 \pm 0.030$ & $0.011 \pm 0.002$ & $0.080 \pm 0.042$ & $0.011 \pm 0.001^{* * *}$ \\
\hline CS-HexFr 10 mg & $0.138 \pm 0.021$ & $0.033 \pm 0.014$ & $0.116 \pm 0.045$ & $0.022 \pm 0.005$ & $0.210 \pm 0.122$ & $0.024 \pm 0.006^{* * *}$ \\
\hline \multicolumn{7}{|l|}{ Intestine } \\
\hline Vehicle & $0.289 \pm 0.181$ & $0.119 \pm 0.053$ & $0.162 \pm 0.071$ & $0.001 \pm 0.000$ & $0.033 \pm 0.020$ & $0.053 \pm 0.025$ \\
\hline Cisplatin & $0.203 \pm 0.034$ & $0.060 \pm 0.001$ & $0.159 \pm 0.051$ & $0.341 \pm 0.061$ & $0.071 \pm 0.005$ & $0.503 \pm 0.078^{\# \# \#}$ \\
\hline MCP 30 mg & $0.167 \pm 0.047$ & $0.013 \pm 0.001$ & $0.023 \pm 0.020$ & $0.021 \pm 0.010$ & $0.421 \pm 0.402$ & $0.040 \pm 0.005^{* * *}$ \\
\hline CS-HexFr 10 mg & $0.392 \pm 0.052$ & $0.254 \pm 0.154$ & $0.818 \pm 0.232$ & $0.104 \pm 0.016$ & $0.294 \pm 0.144$ & $0.105 \pm 0.011^{* * *}$ \\
\hline
\end{tabular}

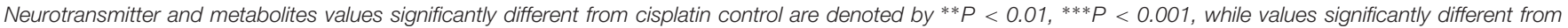
basal level are indicated by ${ }^{\# \#} P<0.05$, \#\#\# $P$ < 0.001 (ANOVA followed by Tukey's post hoc analysis; $n=6-8$ ).

CS-HexFr at the dose of $10 \mathrm{mg} / \mathrm{kg}$ once and twice daily dosing provided up to $58.53 \%$ ( $17 \pm 3.4$ episodes $)$ and $65.85 \%(14.1 \pm 2.9$ episodes) protection, respectively (Table 1). The $n$-hexane extract has been reported to contain cannabis major active constituent Delta-9-tetrahydrocannabinol $\left(\Delta^{9}\right.$ - THC) which has been in use for the treatment of various diseases including management of CIV in clinics and the enhancement of appetite. $\Delta^{9}-$ THC is also found to have anti-inflammatory, spasmolytic, analgesic, and anti-glaucoma activity (Carlini, 2004). Furthermore, Sallan et al. (1975) have shown that the active component of CS ( $\Delta^{9}$ - THC) has anti-emetic effects, by its ability to stimulate presynaptic cannabinoid $\mathrm{CB}_{1}$ receptors (Darmani, 2001) and subsequent inhibition of monoamine neurotransmitters release (Darmani et al., 2003).

Metoclopramide (MCP), a clinically relevant anti-emetic with dopamine and $5-\mathrm{HT}_{3}$ receptor antagonist properties (Al-Zubaidy and Mohammad, 2005), was used as a positive control. The dose of MCP that we selected is higher than that required to antagonize cisplatin-induced emesis in other species (Zhang et al., 2006), and was based on a previous study in the pigeon showing activity against reserpine-induced emesis (Coronas et al., 1975). The metoclopramide was selected as standard drug because of the intrinsic emetic activity of $5 \mathrm{HT}_{3}$ receptor antagonists in pigeon (unpublished data). 
Cisplatin which belongs to the highly emetogenic class of cancer chemotherapeutic agents is in use for the screening of anti-emetic potential of current anti-emetic agents. Cisplatin $(4-10 \mathrm{mg} / \mathrm{kg}$ ) has been used by several investigators to induce vomiting in pigeons (Feigenbaum et al., 1989b; Wolff and Leander, 1995). However, Tanihata et al. (2000) used a lower dose of $4 \mathrm{mg} / \mathrm{kg}$ and longer observation periods $(\sim 72 \mathrm{~h})$. In fact, our colony of pigeons had shown a reliable vomiting response at $7 \mathrm{mg} / \mathrm{kg}$ up to $24 \mathrm{~h}$ of observation period (Ullah et al., 2014, 2015) and we therefore, used the dose of $7 \mathrm{mg} / \mathrm{kg}$ to induce emesis.

The current evidences about the involvement of neurotransmitters implicate the overlap of serotonergic, dopaminergic, and neurokininergic systems in the whole time course of cisplatin-induced vomiting (Darmani et al., 2009). The neurotransmitters especially 5HT (serotonin) and dopamine are considerable mediators of vomiting induced by cancer chemotherapy treatments (Johnston et al., 2014) and the detection of neurotransmitter metabolites in biological samples suggest the involvement of serotonin and dopamine in the triggering of vomiting response (Veyrat-Follet et al., 1997; Gralla et al., 1999). Furthermore, substance P also plays an important role in the mediation of the vomiting response. Since increased turnover of 5-HT, dopamine and substance $\mathrm{P}$ occur during both phases of vomiting in the brainstem and intestine in vomit-competent animals as well as humans (Darmani et al., 2009), further investigations are needed to investigate the effects of substance $\mathrm{P}$ in

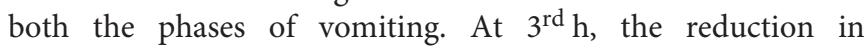
the concentration of 5HT and the metabolite 5HIAA by CS-HexFr (10 mg) in the brain areas (AP and BS) and intestine (Table 3) correlate well with the suppression of the vomiting response, where serotonin has been reported to be the mediator of acute vomiting response of cisplatininduced vomiting (Higgins et al., 2012; Ullah et al., 2014). Similarly, the reduction in the concentration of dopamine in the area postrema and 5HT concentration in the brain areas and intestine at $18^{\text {th }} \mathrm{h}$ of cisplatin administration (Table 4) further support the anti-emetic action of CS-HexFr later in the emetic episode. At $3^{\text {rd }} \mathrm{h}$ of cisplatin administration, dopamine concentration has been quantified as significantly high $(P<0.001)$ in the area postrema, brain stem and intestine, which is paradoxical with regard to the anti-emetic effect of CS-HexFr. The paradox can be hypothesized of (1) Switching of efficacy from agonist to antagonist of cannabis active constituent (2) Differential interaction with Gi or Gs signal transduction proteins (3) Pharmacokinetic factors, etc. (Darmani, 2010).

A number of studies suggest the involvement of $\mathrm{CB}_{1}$ receptor activation for the anti-emetic action of Cannabis sativa ( $\Delta^{9}$-THC) (Darmani, 2001; Van Sickle et al., 2003) against

\section{REFERENCES}

Ali, M., Muhammad, S., Shah, M. R., Khan, A., Rashid, U., Farooq, U., et al. (2017). Neurologically potent molecules from Crataegus oxyacantha; isolation, anticholinesterase inhibition, and molecular docking. Front. Pharmacol. 8:327. doi: 10.3389/fphar.2017.00327 various emetogenic agents. The $\mathrm{CB}_{1}$ receptors are co-localized with $5 \mathrm{HT}_{3}$ receptors in the nucleus tractus solitarius (NTS) in the brain stem and Gastrointestinal tract (GIT) (Hermann et al., 2002), where the action of THC on these receptors inhibit the release of monoamines, especially 5HT, in the least shrew model (Darmani and Johnson, 2004) and Pigeon model (present study). Our study provides further evidence for the involvement of serotonin and dopamine (and their metabolites) in the control of cisplatin-induced emesis over a $24 \mathrm{~h}$ period in the pigeon. Our current data in Figure 1 $(\mathrm{VEH} / \mathrm{Pt})$ does not support the time periods as acute- and delayed-emetic phases, which indicate that the acute emetic phase is probably between first and second hour post-cisplatin injection, and there is no identifiable delayed phase since the frequency of emesis/jerks gradually declines and there is no upsurge of emesis per hour later on through $24 \mathrm{~h}$ observation period. The two time points, i.e., $3^{\text {rd }}$ and $18^{\text {th }} \mathrm{h}$ post-cisplatin administration have been selected to find a clue for any mechanistic differences in the mediation of cisplatin-induced vomiting throughout the observation period in pigeons.

In summary, this study provides evidence for the involvement of serotonin and dopamine differentially at the two different time points in the triggering of vomiting response by cisplatin in pigeons. Furthermore, the suppression of the behavioral signs of cisplatin-induced vomiting by CS-HexFr is supported by attenuation of the cisplatin-induced 5HT upsurge at acute time point $\left(3^{\text {rd }} \mathrm{h}\right)$ and dopamine and 5HT upsurge at delayed time point $\left(18^{\text {th }} \mathrm{h}\right)$.

\section{AUTHOR CONTRIBUTIONS}

IU conceived the project, performed experimental work, data collection, analysis, literature search, and manuscript preparation. FS supervised research work, helped in study design, and drafted the final version of the manuscript. MS, JA, and MA helped in project design, behavioral experiments, performed statistical analysis, and corrected the final version of the manuscript. All authors read and approved the final manuscript for publication.

\section{ACKNOWLEDGMENTS}

We sincerely thank Higher Education Commission of Pakistan for sponsoring the studies. We are thankful to Korea United Pharm, Inc., Korea for donating Cisplatin active material for this study. The contribution from Dissertation of IU is also hereby acknowledged.

Al-Zubaidy, M. H., and Mohammad, F. K. (2005). Metoclopramide-induced central nervous system depression in the chicken. BMC Vet. Res. 1:6. doi: 10.1186/1746-6148-1-6

Ayaz, M., Junaid, M., Ullah, F., Subhan, F., Sadiq, A., Ali, G., et al. (2017). Anti-Alzheimer's studies on $\beta$-sitosterol isolated from Polygonum hydropiper L. Front. Pharmacol. 8:697. doi: 10.3389/fphar.2017.00697 
Brown, A. (2007). Novel cannabinoid receptors. Br. J. Pharmacol. 152, 567-575. doi: 10.1038/sj.bjp.0707481

Carlini, E. (2004). The good and the bad effects of (-) trans-delta-9tetrahydrocannabinol ( 9-THC) on humans. Toxicon 44, 461-467. doi: 10.1016/ j.toxicon.2004.05.009

Coronas, R., Pitarch, L., and Mallol, J. (1975). Blockade of reserpine emesis in pigeons by metoclopramide. Eur. J. Pharmacol. 32, 380-382. doi: 10.1016/00142999(75)90309-X

Cubeddu, L., O'connor, D., Hoffmann, I., and Parmer, R. (1995). Plasma chromogranin A marks emesis and serotonin release associated with dacarbazine and nitrogen mustard but not with cyclophosphamide-based chemotherapies. Br. J. Cancer 72, 1033-1038. doi: 10.1038/bjc.1995.457

Darmani, N. (2001). Delta (9)-tetrahydrocannabinol and synthetic cannabinoids prevent emesis produced by the cannabinoid $\mathrm{CB}_{1}$ receptor antagonist/inverse agonist SR 141716A. Neuropsychopharmacology 24, 198-203. doi: 10.1016/ S0893-133X(00)00197-4

Darmani, N., Janoyan, J., Kumar, N., and Crim, J. (2003). Behaviorally active doses of the CB1 receptor antagonist SR 141716A increase brain serotonin and dopamine levels and turnover. Pharmacol. Biochem. Behav. 75, 777-787. doi: 10.1016/S0091-3057(03)00150-3

Darmani, N., and Johnson, J. (2004). Central and peripheral mechanisms contribute to the antiemetic actions of delta-9-tetrahydrocannabinol against 5-hydroxytryptophan-induced emesis. Eur. J. Pharmacol. 488, 201-212. doi: 10.1016/j.ejphar.2004.02.018

Darmani, N., Zhao, W., and Ahmad, B. (1999). The role of D2 and D3 dopamine receptors in the mediation of emesis in Cryptotis parva (the least shrew). J. Neural. Transm. 106, 1045-1061. doi: 10.1007/s007020050222

Darmani, N. A. (2010). Cannabinoid-induced hyperemesis: a conundrumfrom clinical recognition to basic science mechanisms. Pharmaceuticals 3, 2163-2177. doi: 10.3390/ph3072163

Darmani, N. A., Crim, J. L., Janoyan, J. J., Abad, J., and Ramirez, J. (2009). A re-evaluation of the neurotransmitter basis of chemotherapy-induced immediate and delayed vomiting: evidence from the least shrew. Brain Res. 1248, 40-58. doi: 10.1016/j.brainres.2008.10.063

Diemunsch, P., and Grelot, L. (2000). Potential of substance P antagonists as antiemetics. Drugs 60, 533-546. doi: 10.2165/00003495-200060030-00002

Duvernoy, H. M., and Risold, P.-Y. (2007). The circumventricular organs: an atlas of comparative anatomy and vascularization. Brain Res. Rev. 56, 119-147. doi: 10.1016/j.brainresrev.2007.06.002

Endo, T., Takahashi, M., Minami, M., Yoshioka, M., Saito, H., and Parvez, S. (1993). Effects of anticancer drugs on enzyme activities and serotonin release from ileal tissue in ferrets. Biogenic Amines 9, 479-489.

Feigenbaum, J. J., Richmond, S., Weissman, Y., and Mechoulam, R. (1989a). Inhibition of cisplatin-induced emesis in the pigeon by a non-psychotropic synthetic cannabinoid. Eur. J. Pharmacol. 169, 159-165. doi: 10.1016/00142999(89) $90828-5$

Feigenbaum, J. J., Richmond, S. A., Weissman, Y., and Mechoulam, R. (1989b). Inhibition of cisplatin-induced emesis in the pigeon by a non-psychotropic synthetic cannabinoid. Eur. J. Pharmacol. 169, 159-165. doi: 10.1016/00142999(89)90828-5

Foss, J. F., Yuan, C. S., Roizen, M. F., and Goldberg, L. I. (1998). Prevention of apomorphine-or cisplatin-induced emesis in the dog by a combination of methylnaltrexone and morphine. Cancer Chemother. Pharmacol. 42, 287-291. doi: $10.1007 /$ s002800050819

Gralla, R. J., Osoba, D., Kris, M. G., Kirkbride, P., Hesketh, P. J., and Chinnery, L. W. (1999). Recommendations for the use of antiemetics: evidence-based, clinical practice guidelines. J. Clin. Oncol. 17, 2971-2994. doi: 10.1200/JCO. 1999.17.9.2971

Grunberg, S. M., and Koeller, J. M. (2003). Palonosetron: a unique 5HT3-receptor antagonist for the prevention of chemotherapy-induced emesis. Expert Opin. Pharmacother. 4, 2297-2303. doi: 10.1517/14656566.4. 12.2297

Hermann, H., Marsicano, G., and Lutz, B. (2002). Coexpression of the cannabinoid receptor type 1 with dopamine and serotonin receptors in distinct neuronal subpopulations of the adult mouse forebrain. Neuroscience 109, 451-460. doi: 10.1016/S0306-4522(01)00509-7

Hesketh, P. J. (2008). Chemotherapy-induced nausea and vomiting. N. Engl. J. Med. 358, 2482-2494. doi: 10.1056/NEJMra0706547
Hesketh, P. J., Grunberg, S. M., Gralla, R. J., Warr, D. G., Roila, F., De Wit, R., et al. (2003a). The oral neurokinin-1 antagonist aprepitant for the prevention of chemotherapy-induced nausea and vomiting: a multinational, randomized, double-blind, placebo-controlled trial in patients receiving highdose cisplatin-the Aprepitant Protocol 052 Study Group. J. Clin. Oncol. 21, 4112-4119. doi: 10.1200/JCO.2003.01.095

Hesketh, P. J., Van Belle, S., Aapro, M., Tattersall, F. D., Naylor, R. J., and Hargreaves, R. (2003b). Differential involvement of neurotransmitters through the time course of cisplatin-induced emesis as revealed by therapy with specific receptor antagonists. Eur. J. Cancer 39, 1074-1080. doi: 10.1016/S09598049(02)00674-3

Higgins, G., Kilpatrick, G., Bunce, K., Jones, B., and Tyers, M. (2012). 5HT3 receptor antagonists injected into the area postrema inhibit cisplatin induced emesis in the ferret. Br. J. Pharmacol. 97, 247-255. doi: 10.1111/j.1476-5381. 1989.tb11948.x

Johnston, K. D., Lu, Z., and Rudd, J. A. (2014). Looking beyond 5-HT3 receptors: A review of the wider role of serotonin in the pharmacology of nausea and vomiting. Eur. J. Pharmacol. 722, 13-25. doi: 10.1016/j.ejphar.2013.10.014

Karten, H. J., and Hodos, W. (1967). A Stereotaxic Atlas of the Brain of the Pigeon:(Columba Livia). Baltimore, MD: Johns Hopkins University Press.

Le Moine, C., and Bloch, B. (2004). D1 and D2 dopamine receptor gene expression in the rat striatum: sensitive cRNA probes demonstrate prominent segregation of D1 and D2 mRNAs in distinct neuronal populations of the dorsal and ventral striatum. J. Comp. Neurol. 355, 418-426. doi: 10.1002/cne.903550308

Mackie, K., and Stella, N. (2006). Cannabinoid receptors and endocannabinoids: evidence for new players. AAPS J. 8, 298-306. doi: 10.1007/BF02854900

Martinez, A., Morgese, M., Pisanu, A., Macheda, T., Paquette, M., Seillier, A., et al. (2015). Activation of PPAR gamma receptors reduces levodopa-induced dyskinesias in 6-OHDA-lesioned rats. Neurobiol. Dis. 74, 295-304. doi: 10.1016/ j.nbd.2014.11.024

Miller, A. D., and Leslie, R. A. (1994). The area postrema and vomiting. Front. Neuroendocrinol. 15, 301-320. doi: 10.1006/frne.1994.1012

Minami, M. (1995). "How do toxic emetic stimuli cause 5-HT release in the gut and brain?" in Serotonin and the Scientific Basis of Antiemetic Therapy, eds D. J. M. Reynolds, P. L. R. Andrews, and C. J. Davis (Oxford: Oxford Clinical Communications), 68-76.

Minami, M., Endo, T., Hirafuji, M., Hamaue, N., Liu, Y., Hiroshige, T., et al. (2003). Pharmacological aspects of anticancer drug-induced emesis with emphasis on serotonin release and vagal nerve activity. Pharmacol. Ther. 99, 149-165. doi: 10.1016/S0163-7258(03)00057-3

Miner, W. D., and Sanger, G. J. (2012). Inhibition of cisplatin-induced vomiting by selective 5-hydroxytryptamine M-receptor antagonism. Br. J. Pharmacol. 88, 497-499. doi: 10.1111/j.1476-5381.1986.tb10228.x

Osinski, M. A., Seifert, T. R., Shaughnessy, T. K., Gintant, G. A., and Cox, B. F. (2003). Emetic liability testing in ferrets. Curr. Protoc. Pharmacol. 5, 31-35. doi: 10.1002/0471141755.ph0531s20

Osinski, M. A., Uchic, M. E., Seifert, T., Tk Nakane, M., Cox, B., Brioni, J., et al. (2005). Dopamine D2, but not D4, receptor agonists are emetogenic in ferrets. Pharmacol. Biochem. Behav. 81, 211-219. doi: 10.1016/j.pbb.2005. 03.012

O’sullivan, S. E. (2016). An update on PPAR activation by cannabinoids. Br. J. Pharmacol. 173, 1899-1910. doi: 10.1111/bph.13497

Pacher, P., Batkai, S., and Kunos, G. (2006). The endocannabinoid system as an emerging target of pharmacotherapy. Pharmacol. Rev. 58, 389-462. doi: 10. $1124 /$ pr.58.3.2

Percie du Sert, N., Rudd, J. A., Apfel, C. C., and Andrews, P. L. R. (2011). Cisplatininduced emesis: systematic review and meta-analysis of the ferret model and the effects of 5-HT3 receptor antagonists. Cancer Chemother. Pharmacol. 67, 667-686. doi: 10.1007/s00280-010-1339-4

Pertwee, R. (2006). Cannabinoid pharmacology: the first 66 years. Br. J. Pharmacol. 147, 163-171. doi: 10.1038/sj.bjp.0706406

Preziosi, P., Amanto, M. D., Carmine, R. D., Martire, M., Pozzoli, G., and Navarra, P. (1992). The effects of 5-HT3 receptor antagonists on cisplatininduced emesis in the pigeon. Eur. J. Pharmacol. 221, 343-350. doi: 10.1016/ 0014-2999(92)90721-F

Saito, R., Takano, Y., and Kamiya, H. (2003). Roles of substance P and NK1 receptor in the brainstem in the development of emesis. J. Pharmacol. Sci. 91, 87-94. doi: $10.1254 /$ jphs. 91.87 
Sallan, S., Zinberg, N., and Frei, E. (1975). Antiemetic effect of delta-9tetrahydrocannabinol in patients receiving cancer chemotherapy. N. Engl. J. Med. 293, 795-797. doi: 10.1056/NEJM197510162931603

Schofferman, J. A. (1976). A clinical comparison of syrup of ipecac and apomorphine use in adults. JACEP 5, 22-25. doi: 10.1016/S0361-1124(76) 80161-X

Stampanoni Bassi, M., Sancesario, A., Morace, R., Centonze, D., and Iezzi, E. (2017). Cannabinoids in Parkinson's disease. CNC Neurol. Disord. Drug Targets 2, 21-29. doi: 10.1089/can.2017.0002

Tanihata, S., Igarashi, H., Suzuki, M., and Uchiyama, T. (2000). Cisplatin-induced early and delayed emesis in the pigeon. Br. J. Pharmacol. 130, 132-138. doi: $10.1038 /$ sj.bjp.0703283

Ullah, I. (2013). Evaluation of Some Selected Medicinal Plants and their Combinations in Cisplatin Induced Vomiting in Vomit Model(s); Behavioral Neurochemical Correlates. Ph.D. thesis, University of Peshawar, Peshawar.

Ullah, I., Subhan, F., Ayaz, M., Shah, R., Ali, G., Haq, I. U., et al. (2015). Antiemetic mechanisms of zingiber officinale against cisplatin induced emesis in the pigeon; behavioral and neurochemical correlates. BMC Complement. Altern. Med. 15:34. doi: 10.1186/s12906-015-0556-0

Ullah, I., Subhan, F., Rauf, K., Badshah, A., and Ali, G. (2012). Role of gastrointestinal motility/gastric emptying in cisplatin-induced vomiting in pigeon. Afr. J. Pharma Pharmacol. 6, 2592-2599. doi: 10.5897/AJPP 12.530

Ullah, I., Subhan, F., Rudd, J. A., Rauf, K., Alam, J., Shahid, M., et al. (2014). Attenuation of cisplatin-induced emetogenesis by standardized Bacopa monniera extracts in the pigeon: behavioral and neurochemical correlations. Planta Med. 80, 1569-1579. doi: 10.1055/s-00341383121

Van Sickle, M. D., Oland, L. D., Mackie, K., Davison, J. S., and Sharkey, K. A. (2003). $\Delta 9$-Tetrahydrocannabinol selectively acts on $\mathrm{CB1}$ receptors in specific regions of dorsal vagal complex to inhibit emesis in ferrets. Am. J. Physiol. Gastrointest. Liver Physiol. 285, G566-G576. doi: 10.1152/ajpgi.00113.2003

Veyrat-Follet, C., Farinotti, R., and Palmer, J. L. (1997). Physiology of chemotherapy-induced emesis and antiemetic therapy. Predictive models for evaluation of new compounds. Drugs 53, 206-234. doi: 10.2165/00003495199753020-00003

Wolff, M., and Leander, J. (1995). Comparison of the antiemetic effects of a 5-HT1A agonist, LY228729, and 5-HT3 antagonists in the pigeon. Pharmacol. Biochem. Behav. 52, 571-575. doi: 10.1016/0091-3057(95)00142-J

Wolff, M. C., and Leander, J. D. (1997). Effects of a 5-HT1A receptor agonist on acute and delayed cyclophosphamide-induced vomiting. Eur. J. Pharmacol. 340, 217-220. doi: 10.1016/S0014-2999(97)01401-5

Yoshikawa, T., Yoshida, N., and Hosoki, K. (1996). Involvement of dopamine D3 receptors in the area postrema in $\mathrm{R}(+)$ 7-OH-DPAT induced emesis in the ferret. Eur. J. Pharmacol. 301, 143-149. doi: 10.1016/0014-2999(96)00061-1

Zhang, F., Wang, L., Yang, Z. H., Liu, Z. T., and Yue, W. (2006). Value of mink vomit model in study of anti-emetic drugs. World J. Gastroenterol. 12, 1300-1302. doi: 10.3748/wjg.v12.i8.1300

Conflict of Interest Statement: The authors declare that the research was conducted in the absence of any commercial or financial relationships that could be construed as a potential conflict of interest.

Copyright (C) 2018 Ullah, Subhan, Alam, Shahid and Ayaz. This is an open-access article distributed under the terms of the Creative Commons Attribution License (CC BY). The use, distribution or reproduction in other forums is permitted, provided the original author(s) and the copyright owner are credited and that the original publication in this journal is cited, in accordance with accepted academic practice. No use, distribution or reproduction is permitted which does not comply with these terms. 